\title{
JENIS PARASITOID TELUR HAMA Conopomorpha cramerella PADA TANAMAN KAKAO DI SULAWESI UTARA
}

\section{TYPE OF PARASITPID EGG PEST OF CONOPOMORPHA CRAMERELLA AT CROP OF CACAO IN NORTH SULAWESI}

\author{
D. Kandowangko, R. Engka, dan J. Rimbing \\ Jurusan Hama dan Penyakit Tumbuhan Fakultas Pertanian UNSRAT Manado_95115
}

\begin{abstract}
Controlling of pestpopulationon cocoa fruitis moreeffectiveandefficientusingeggparasitoid.Parasitoid type on cocoa fruit pestC. cramerella in North Sulawesi has not been investigated. Investigation of parasitoid type on cocoa fruit pestC. cramerella in North Sulawesi was initiated by collecting cacao pods to observethe eggs ofCoryra cephalonicaandtrapingof itseggs. Samples of cocoa fruits were collected three times. Each collecting samples, the cocoa fruitswere gathered between 45-80each time.The Coryra cephalonicaeggswere trapped between4000-600of each trapping. The result showed that only12eggsthat grew into theperfect stage, whereas eggs which were not grown to perfect stage were614eggs. The rest of the eggs were not grown. The finding indicated thatparasitoid type on cocoa fruit pestC. cramerella in North Sulawesiwas not found. Rainy season during collecting samples could cause the eggs of $C$. cramerellanot grown.
\end{abstract}

Keyword: Typeparasitoid, C. cramerella

\begin{abstract}
ABSTRAK
Untuk menekan populasi hama penggerek buah kakao yang lebih efektif dan efisien dapat dilakukan dengan menggunakan parasitoid telur. Jenis parasitoid hama penggerek buah kakao, C. cramerella di Sulawesi Utara belum diketahui. Untuk mendapatkan data parasitoid dilakukan pengambilan contoh buah untuk mengamati telur-telur $C$. cephalonica dan traping telur Coryra cephalonica. Lokasi penelitian adalah Desa Kumu Kabupaten Minahasa, Desa Sapa dan Pungkol Kabupaten Minahasa Selatan. Penelitian dilakukan selama tiga kali dengan mengambil contoh buah kakao 45 - 80 buah per pengambilan dan traping telur berkisar $4000-600$ butir per peletakkan. Dari sejumlah telur yang ditemukan hanya 1 - 2 butir yang berkembang menjadi sempurna, sedangkan telur yang tidak berkembang secara sempurna lebih tinggi berkisar antara $6-14$ butir. Jumlah telur yang tidak berkembang secara sempurna cukup tinggi, hal ini merupakan salah satu faktor pembatas, sehingga belum ditemukan parasitoid telur hama penggerek buah kakao. Selama penelitian berlangsung terjadi musim hujan, hal ini yang mungkin berpengaruh terhadap perlkembang telur C. cramerella. Pengambilan contoh pertama terdapat bekas telur-telur $\mathrm{C}$. cramerella yang terparasit dan pada periode terjadi musim kemarau. Demikian pula dengan melakukan traping telur, C. cephalonica pada pertanaman kakao diketiga lokasi sebanyak 3 kali untuk setiap lokasi belum ditemukan parasitoid yang memarasit telur $C$. cephalonica. ..
\end{abstract}

Kata kunci: Jenis Parasitoid, C. cramerella 


\section{PENDAHULUAN}

Di Indonesia, produksi kakao masih tergolong rendah $900 \mathrm{~kg} \mathrm{bij/ha/tahun.} \mathrm{Angka} \mathrm{ini}$ masih jauh di bawah rata-rata potensi yang diharapkan, yakni $2000 \mathrm{~kg} / \mathrm{ha} / \mathrm{tahun}$. Rendahnya produksi kakao diantaranya adanya serangan hama penggerek buah kakao, Conopomorpha cramerella. Di Sulawesi Utara, terdapat beberapa hama yang menyerang tanaman kakao, tetapi hama yang cukup serius menyerang pertanaman kakao adalah hama penggerek buah kakao, C. cramerella. Hama penggerek buah kakao telah menyebar pada pertanaman kakao di Sulawesi Utara (Anonim, 2006).

Secara ekonomis hama penggerek buah kakao merupakan serangga hama penting, karena hama ini menggerek dan memakan daging buah, dan biji buah. Pada serangan berat, biji sulit dikeluarkan karena saling lengket dengan kulit buah. Akibat serangan hama penggerek buah kakao dapat menurunkan produksi sampai $80 \%$ (Wiryadiputra dan Atawinata, 1998). Di Sulawesi Utara, Kabupaten Bolaang Mongondow persentase kerusakan buah sebesar $12 \%$, sedangkan di Kabupaten Minahasa persentase kerusakan buah lebih tinggi, yaitu mencapai 100\% (Tulung, 2000). Sampai saat ini perkebunan kakao di Sulawesi Utara menjadi acaman dengan adanya hama penggerek buah kakao. Sulistyowati dkk. (1995) melaporkan hasil survei pada tahun 1994 menunjukkan bahwa hama pengerek buah kakao terdapat di delapan Propinsi, yaitu Maluku, Sulawesi Utara, Sulawesi Tengah, Kalimatan Timur, Sumatera Barat, Sumatera Utara dan Bengkulu. Di Indonesia, areal tanaman kakao yang terserang penggerek buah kakao dengan intensitas serangan tinggi 348.000 ha atau $40 \%$ dari total areal kakao. Dengan asumsi tingkat kehilangan hasil $40 \%$, akan menyebabkan kehilangan hasil sebesar 125 ribu ton per tahun atau senilai 1,25 triliun (Wahyudi dan Rahardjo, 2008).

Untuk menekan populasi hama, maka dilakukan tindakan pengendalian terhadap hama penggerek buah kakao. Pengendalian hama penggerek buah kakao, C. cramerella di Sulawesi Utara masih melakukan perampasan buah, dan aplikasi insektisida. Kedua cara tidak semua petani melakukan pengendalian terhadap hama penggerek buah kakao. Penelitian oleh Tulung (2000) melaporkan bahwa aplikasi insektisida Azodrin, Gusadrin, Tamaron, dan Lannate melalui infus akar, batang, dan penyemprotan langsung pada pertanaman kakao dapat menekan serangan hama penggerek buah kakao sampai $4,60 \%$ pada infus akar. Kelemahan dalam aplikasi insektisida adanya residu produk yang dihasilkan Kombinasi pengendalian dengan panen sering, pemangkasan, pumupukan dan sanitasi hanya mampu menekan serangan penggerek buah kakao di bawah $5 \%$ (Wahyudi dan Rahardjo, 2008).

Alternatif lain yang dapat ditempuh untuk menekan populasi hama penggerek buah kakao adalah pemanfaatan parasitoid telur. Namun data tentang parasitoid telur yang memarasit telur-telur hama penggerek buah kakao di Indonesia terutama di Sulawesi Utara belum pernah dilaporkan. DeBach (1964); Kalshoven (1981); Nagaraja (1978) mengemukakan bahwa parasitoid Trichogrammatidae memarasit telur hama Lepidoptera dan Coloeptera. Terdapat dua genus parasitoid yang terkenal memarasit serangga hama tanaman pertanian adalah Trichogramma sp dan Trichogrammatoidea sp (DeBach, 1964; Clausen, 1940). Di Indonesia, genus Trichogramma sp., dan Trichogrammatoidea sp. telah banyak dilaporkan memarasit serangga hama pada ordo Lepidoptera di pertanaman padi sawah, jagung, tebu dan kedelai. Parasitoid telur yang memarasit hama penggerek buah kakao, $C$. cramerella di Malaysia hanya 1 jenis yakni Trichogrammatoidea bactrae fumata (Anonim, 1998). Jumlah jenis parasitoid yang memarasit telur hama penggerek buah kakao berbeda dengan yang di laporkan oleh Abdoellah (2008) bahwa parasitoid yang memarasit telur hama penggerek buah kakao adalah Trichogramma pretiosa, Trichogramma australiacum, Trichogramma minitum, dan Trichogrammatoide nana.

Penelitian ini bertujuan untuk mengetahui jenis parasitoid yang memarasit telur hama penggerek buah kakao di Sulawesi Utara. 


\section{METODE PENELITIAN}

Penelitian telah dilaksanakan pada sentra produksi tanaman kakao di Desa Kumu Kabupaten Minahasa, Desa Pungkol dan Sapa Minahasa Selatan. Selanjutnya dilaksanakan penelitian di laboratorium Entomologi dan Hama Tumbuhan Fakultas Pertanian Unsrat. Kegiatan penelitian terdiri dari pengambilan contoh buah kakao dan traping telur $C$. cephalonica. Penelitian ini berlangsung selama kurang lebih 6 bulan. Tahap penelitian diurai berikut.

\section{Pengambilan Contoh Buah Kakao}

Pengambilan contoh buah kakao di lapangan berukuran panjang di atas $8 \mathrm{~cm}$. Maksud dilakukan pengambilan contoh buah kakao di atas 8 $\mathrm{cm}$, karena buah tersebut sebagai tempat meletakkan telur imago betina. Buah kakao yang diambil dari lapang, kemudian di bawah ke laboratorium dan diamati dibawah mikroskop binokuler. Telur-telur $C$. cramerella yang terdeteksi pada buah kakao dipisahkan, kemudian dimasukkan gelas vial atau rol film,. setiap vial dimasukkan sebanyak 1 -2 butir telur. Pengamatan mengenai ada-tidaknya parasitoid dilakukan setiap hari selama 7 - 10 hari. Setiap lokasi untuk mendapatkan contoh buah kakao dilakukan secara garis diagonal. Banyak contoh buah kakao yang diambil di lapangan tergantung pada kondisi buah di lokasi. Untuk lokasi Pungkol diperoleh sebanyak70-80 buah, Sapa 56-73 buah, 45-70 buah kakao untuk Kumu. Pengambilan contoh buah kakao dilakukan sebanyak 3 kali dengan interval waktu sebulan sekali.

\section{Traping Telur C. cephalonica}

Telur-telur C. cephalonica hasil perbanyakan di Laboratorium, kemudian dilakukan traping untuk mendapatkan data parasitoid telur Tichogrammatidae. Peletakkan telur dilakukan sepanjang garis irisan garis diagonal sebanyak 20 30 kontainer yang berdiameter $10 \times 12,5 \mathrm{~cm}$, bagian atas dan bawah kontainer dibuka. Telurtelur yang berada dalam pias sebanyak 100 butir, kemudian ditempelkan pada container. Satu kontainer ditempelkan sebanyak 2 pias yang berisi masing-masing telur 200 butir. Setiap titik diletakkan sebanyak 200 butir telur $C$. cephalonica, sehingga untuk 1 lokasi diperlukan sebanyak 4000 6000 butir telur per pelepasan. Umur telur yang digunakan dalam percobaan ini berumur 24 jam, lamanya telur di lapangan atau pertanaman kakao selama 4 hari, kemudian telur $C$. cepahalonica tersebut diambil kembali dan dibawah ke laboratorium untuk mengetahui ada- tidaknya jenis parasitoid dan parasitisasinya. Traping telur $C$. cephalonica dilakukan sebanyak 3 kali dengan interval waktu sebulan sekali.

\section{HASIL DAN PEMBAHASAN}

\section{Pengambilan Contoh Buah Kakao}

Pengambilan contoh buah kakao dilakukan sebanyak 3 kali dengan jumlah buah yang diambil setiap kali pengambil bervariasi, hal ini tergantung pada jumlah buah yang berukuran panjang di atas $8 \mathrm{~cm}$. Jumlah buah kakao yang diambil di Desa Pungkol selama tiga kali pengambilan dapat diikuti pada Tabel 1

Tabel 1. Jumlah Buah Kakao dan Telur Hama Penggerek Buah Kakao di Desa Pungkol Kecamatan Tatapaan (Table 1. Numbers Of Cacao Pods And Eggs Of Cacao Pod Borer In Pungkol District Tatapaan)

\begin{tabular}{lllll}
\hline & & & \multicolumn{2}{c}{ Jumlah Telur } \\
\cline { 4 - 5 } No & Waktu Pengambilam & Jumlah Buah & Fertil & Sempurna \\
\hline 1 & Pertama & 80 & 9 & 2 \\
2 & Kedua & 70 & 13 & 2 \\
3 & Ketiga & 78 & 15 & 1 \\
\hline
\end{tabular}


Tabel 2. Jumlah Buah Kakao dan Telur Hama Penggerek Buah Kakao di Desa Sapa Kecamatan Tengah (Table 2. Numbers Of Cacao Pods And Eggs Of Cacao Pod Borer In Sapa)

\begin{tabular}{ccccc}
\hline & & & \multicolumn{2}{c}{ Jumlah Telur } \\
\cline { 4 - 5 } No & Waktu Pengambilam & Jumlah Buah & Fertil & Sempurna \\
\hline 1 & Pertama & 66 & 12 & 1 \\
2 & Kedua & 56 & 6 & 0 \\
3 & Ketiga & 77 & 9 & 1 \\
\hline
\end{tabular}

Tabel 3. Jumlah Buah Kakao dan Telur Hama Penggerek Buah Kakao di Desa Kumu Kecamatan Tombariri (Table 3. Numbers Of Cacao Pods And Eggs Of Cacao Pod Borer In Kumu District Tombariri)

\begin{tabular}{ccccc}
\hline & & & \multicolumn{2}{c}{ Jumlah Telur } \\
\cline { 4 - 5 } No & Waktu Pengambilam & Jumlah Buah & Fertil & Sempurna \\
\hline 1 & Pertama & 70 & 12 & 2 \\
2 & Kedua & 60 & 7 & 1 \\
3 & Ketiga & 45 & 9 & 1 \\
\hline
\end{tabular}

Hasil yang diperoleh bahwa jumlah buah kakao yang diperoleh dari lapangan tidak berkorelasi dengan jumlah telur yang diletakkan oleh imago betina pada buah kakao. Jumlah telur yang diletakkan oleh imago betina pada buah kakao tertinggi ditemukan pada pengambilan ketiga sebanyak 16 butir. Dari 16 butir telur yang dapat berkembang secara sempurna hanya 1-2 butir.

Pengambilan contoh buah kakao telah dilakukan pula di Desa Sapa Kecamatan Tengah. Jumlah kakao yang diambil pada ekosistem pertanaman kakao di Desa Sapa dapat diikuti Tabel 2. Sebagaimana yang tercatum pada tabel 2 , bahwa jumlah buah kakao yang ditemukan pada desa Sapa bervariasi diantara 56-77 buah per pengambilan. Telur hama penggerek buah yang berkembang sempurna 0-1 butir tidak terparasit oleh parasitoid. Contoh buah kakao yang diambil pada pertanaman kakao di Desa Kumu bervariasi diantara 45-70. Data mengenai jumlah buah kakao yang diambil pada pertanaman kakao di Desa Kumu dapat diikuti pada Tabel 3.

Sebagaimana yang tercatum pada tabel 1 3 menunjukkan bahwa hasil pengambilan contoh buah kakao menunjukkan bahwa telah ditemukan 2 stadia telur $C$. cramerella yakni telur yang mampu berkembang baik secara sempurna dan tidak mampu berkembang yang disebut fertil. Telur yang berkembang dengan baik lebih jumlahnya lebih rendah dibandingkan dengan telur yang tidak mampu berkembang dengan baik. Telur-telur yang tidak berkembang dengan baik tidak mampu melangsungkan perkembangan menjadi larva. Untuk telur tidak mampu berkembang baik berkisar antara 6 - 15 butir, sedangkan telur C. cramerella berkembang dengan baik hanya 1 - 2 butir.

Dari hasil pemeliharaan telur yang berkembang dengan sempurna selama tiga kali pengambilan contoh buah kakao tidak ditemukan parasitoid yang memarasit telur hama penggerek buah kakao. Telur-telur yang tidak terparasit menetas menjadi larva $C$. cramerella. Belum adanya telur $C$. cramerella yang terparasit oleh parasitoid mungkin jumlah populasi telur sangat rendah sehingga sangat sulit parasitoid menemukan inang tersebut. Pada kenyataan bahwa untuk dapat diparasit telur-telur $C$. cramerella oleh serangga parasitoid harus diperlukan jumlah yang banyak di lapangan. Lim (1986) melaporkan bahwa hama penggerek buah pada musim hujan populasinya tergolong rendah dan serangan tertinggi terjadi pada kondisi tanaman kakao dengan naungan lengkap. Dilain pihak, telur C. cramerella yang belum terparasit dalam penelitian ini mungkin populasi parasitoid pada ekosistem sangat rendah. Sarangga (1999) melaporkan parasitoid Trichogramatodea bactrae fumata mampu memarasit telur $E$. zinckebella pada pertanaman kedelai di Sulawesi Selatan. Pelepasan parasitoid di lapangan sebanyak 22.082 
ekor per ha pada umur $35 \mathrm{hst}$, tingkat parasitasi pada umur tanaman tersebut hanya $4,2 \%$. Hal ini menunjukkan bahwa telur teraprasit sangat rendah meskipun jumlah parasitoid di lepas dilapangan cukup banyak.

Selama pelaksanaan penelitian diketiga lokasi terjadi musim hujan yang cukup tinggi. Adanya curah hujan yang cukup tinggi mungkin telah mempengaruhi terhadap kepadatan populasi parasitoid dan aktivitas dari parasitoid untuk menemukan inang. Parasitoid berukuran kecil dan berada pada permukaan tanaman untuk mencari inang yang akan diparasit, oleh karena itu dengan adanya curah hujan selama penelitian berlangsung populasi parasitoid tertekan. Sedangkan $C$. cramerella, imagonya bersembunyi pada bagian tanaman, dan larvanya berada dalam buah kakao, sehingga pengaruh curah hujan terhadap hama sangat kecil dibandingkan parasitoid.

Hal yang paling penting dengan kaitan dengan curah hujan, mungkin mempengaruhi terhadap perkembangan telur C. cramerella. Bila telur yang ditemukan dan dapat berkembang dengan baik atau sempurna, mungkin telur-telur $C$. cramerella akan diparasit, meskipun populasi parasitoid tersebut rendah. Curah hujan yang cukup tinggi sangat mempengaruhi terhadap kesempurnaan telur yang diletakkan oleh imago betina (Lim, 1986, Anonim, 2002).

\section{Traping Telur C. cephalonica}

Telur-telur C. cephalonica merupakan inang alternatif dari parasitoid telur Trichogrammatidae, sehingga dalam percobaan ini digunakan traping telur $C$. cephalonica yang merupakan salah cara untuk mendapatkan data tentang jenis parasitoid. Digunakan traping telur $C$. cephalonica, karena telur-telur C. cramerella diparasit oleh parasitoid dari jenis Trichogrammatidae. Telur-telur C. cephalonica yang berada dalam pias berukuran $2 \times 4 \mathrm{~cm}$, dan kemudian ditempelkan kedalam kontainer gelas plastik serta selanjutnya dipasang pada pohon kakao untuk mendapatkan serangga parasitoid di lapangan. Traping telur $\mathrm{C}$. cephalonica merupakan inang dari berbagai jenis parasitoid Famili
Trichogrammatidae. Traping telur yang dilakukan pada pertanaman kakao di Desa Pungkol, dan Sapa sebanyak 30 kontainer/ pelepasan.pada .luas areal kurang lebih 1 ha. Hasil pelepasan telur-telur C. cephalonca di Desa Pungkol dan Sapa dapat diikuti pada Tabel 4 Traping telur dilekukan pula di Desa Kumu sebanyak 20 kontainer dengan jumlah telur $C$. cephalonica sebanyak 4000 butir telur per pelepasan. Dari hasil yang diperoleh belum ditemukan telur-telur $C$. cephalonica yang diparasit oleh parasitoid telur.

Selama tiga kali melakukan traping telur di lapangan di Desa Pungkol, Kumu dan Sapa belum ditemukan jenis parasitoid yang memarasit telurtelur C. cephalonica. Sebagaimana yang telah diuraikan terdahulu bahwa selama pelaksanaan penelitian terjadi musim hujan yang merata di ketiga lokasi tersebut. Adanya musim hujan mempengaruhi terhadap aktivitas parasitoid dalam menemukan inang. Disamping itu pula faktor curah hujan berpengaruh terhadap kepadatan populasi parasitoid di lapangan. Sudah tentu dengan adanya curah hujan kepadatan populasi parasitoid akan menjadi rendah, hal ini akan mempengaruhi populasi parasitoid untuk menemukan inang. Bila traping telur dilakukan sebanyak kurang lebih 5 -6 kali dalam 1 bulan mungkin akan ditemukan jenis parasitoid yang memarasit telur $C$. cephalonica. Hal ini harus dilakukan 5-6 kali per bulan secara kontinu, karena diduga populasi parasitoid di lapangan sangat rendah, diakibatkan adanya musim hujan yang mempengaruhi terhadap aktivitas parasitoid dan kepadatan populasi parasitoid.

Dalam melakukan traping telur di lapangan terdapat beberapa pias yang ada telur $C$. cephalonica telah habis di makan atau dimangsai oleh predator. Diduga predator yang memangsai telur-telur $C$. cephalonica adalah jenis Hymenoptera (Semut). Hal ini hanya terjadi pelepasan telur $C$. cephalonica pertama, sedangkan kedua dan ketiga tidak adanya telur dimangsai atau dimakan oleh predator, karena bagian gantungan tali dari container dioles dengan minyak oli. 
Tabel 4. Traping Telur C. Cephalonica Pada Pertanaman Kakao di Desa Pungkol dan Sapa (Table 4. Trapping Of C. cephalonica Eggs on Cacao Field at Pungkol and Sapa)

\begin{tabular}{cccc}
\hline No & Waktu Pelepasan & Jumlah Traping telur & Parasitoid \\
\hline 1 & Pertama & 6000 & 0 \\
2 & Kedua & 6000 & 0 \\
3 & Ketiga & 6000 & 0 \\
\hline
\end{tabular}

Dengan adanya telur $C$. cephalonica yang dimangsai oleh predator, hal ini menunjukkan bahwa telur-telur $\mathrm{C}$. cramerella dimangsai pula oleh predator. Adanya predator sudah tentu akan menekan populasi hama cephalonica

Hasil pengamatan di lapangan di Desa Kumu, Pungkol dan dan Sapa sangat kurang dijumpai pertanaman yang menghasilkan bungabungan. Tanaman bunga-bungaan dapat menghasilkan nektar sebagai makanan dari parasitoid telur yang dewasa atau imago. Dengan sangat kurang ditemukan tanaman bunga-bungan pada ekosistem tanaman kakao, mungkin salah satu faktor yang mempengaruhi terhadap kepadatan populasi parasitoid.

\section{KESIMPULAN}

Hasil penelitian menyimpulkan: (1) Jumlah telur yang ditemukan pada buah kakao masih sangat rendah, dan ditemukan populasi telur yang tidak berkembang dengan baik disebut fertile; (2) Populasi telur hama penggerek buah kakao yang mampu berkembang dengan baik pada buah kakao berkisar $1-2$ butir; (3) Traping telur $C$. cephalonica pada pertanaman kakao di Desa Pungkol, Kumu, dan Sapa belum ditemukan parasitoid yang memarasit telur $\mathrm{C}$. cephalonica.

Untuk dapat mengukapkan jenis parasitoid yang memarasit telur hama penggerek buah kakao, C. cramerella dan traping telur $C$. cephalonica perlu dilakukan penelitian pada musim kemarau.

\section{DAFTAR PUSTAKA}

Abdoellah, S. 2008. Perkembangan Penelitian In kakao Manajemen Agribisnis dari Hulu Hingga Hilir. Editor. Wahyudi, T
T.R Panggabean dan PPujiyanto. Penebar Swadaya. Jakarta.

Anonim, 1984. Pedoman Pengenalan dan Pengendalian Hama dan Penyakit Tanaman Coklat. Departemen Pertanian. Jakarta.

, 1998. Upaya Penanggulangan Hama Penggerek Buah Kakao di Maluku. Badan Penelitian Dan pengembangan Pertanian. Balai Pengkajian Teknologi Pertanian Ambon. Maluku.

2006. Laporan Tahunan. Dinas Perkebunan propinsi Sulawesi Utara. Manado.

DeBach, P. 1964. Succes, Trends and Future Possibities. In Biological Control of Insect Pest and Weeds. Ed.by P. DeBach. Reinhold pub, crop.

Clausen, C.P. 1940. Entomophagous Insect. McGraw-Hill Company, Inc. New York and London.

Herlinda, S., A. rauf, U. Kartosuwondo dan Budihardjo, 1997. Biologi dan Potensi Trichogrammatoidea bactrae-bactrae Hama Penggerek Polong Kedelai. Buletin Hama dan Penyakit Tumbuhan. IPB. Vol 9 No.8

Kalshoven, L.G.E. 1981. The Pests of Crops In Indonesia. PT. Ichtiar Baru Van Hoeve. Jakarta.

Lebang, Medy, San. 1997. Pengaruh Varietas Kakao terhadap Intensitas Kerusakan Hama Conopomorpha cramerella di Minahasa. Skripsi. Fakultas Pertanian Universitas Sam Ratulangi. Manado.

Lim, G.T, 1986. Seasonal Fluctuation of Cocoa Podborer Conophomorpha cranerella Sn. In Taiwan, Sabah Proc Int Conf P. Prot in the Tropies (Extended Abstracts) Malysian plant Prot. Soc. (MAPPS). Kuala Lumpur. 
Meilin Aras, Hidayat Purnama, D. Buchori D, dan U. Kartosuwondo. 2000. Parasitoid Telur pada Hama Kubis, Plutella xylostella (Lepidoptera; Yponomeutidae). Buletin Hama dan Penyakit Tumbuhan. IPB. Bogor. Vol. 12. No.3. Desember 2000.

Nagaraja. H 1978. Studies on Trichogrammatoidea (Hymeneoptera; Trichogrammatidae. Orient Insect $12: 489-530$

Nurindah, OS Bindra, 1989. Studies on Trichogramma spp (Hymenoptera: Trichogrammatidae) in the control of Heliothis armigera (Hubner) (Lepidoptera: Noctuidae). Biotrop Spec. Publ. No. 36 $165-173$

Sarangga, Annie. P. 1999. Pengendalian Penggerek Polong Kedelai Etiella zinkenella Triets pada Pertanaman Kedelai dengan Parasitoid Telur Trichogrammatoidea bactrae fumata. Program Nasional pengendalian hama terpadu. Departemen Pertanian. CisaruaBogor.
Sullistyowati, E. S. Wiryadiputra, A.A Prawoto, T. Sukmaraganda \& C.U. Ginting (1995). Pedomen Teknis Penanggulangan Hama Penggerek Buah Kakao di Indonesia. Edisi I. Pusat Penelitian kopi dan kakao. Jember, $21 \mathrm{P}$.

Sulistyowati, E. 2008. Pengendalian Hama. In Kakao Manajemen Agribisnis dari Hulu Hingga Hilir. Editor. Wahyudi, T T.R Panggabean dan PPujiyanto. Penebar Swadaya. Jakarta.

Tulung, M. .2000. Kajian Pengendalian Hama Pengerek Buah kakao Conopomorpha cramerella di Sulawesi Utara. Media Publikasi IImu Pertanian. Eugenia. Fakultas Pertanian Unsrat. Volumen 6 No. 4

Wiryadiputra dan O. Atmawinata, 1998. Kakao. Pedoman Pengendalian Hama terpadu Tanaman Perkebunan. Pusat Penelitian dan Pengembangan Tanaman Industri. Badan Penelitian dan Pengembangan Pertanaian. Departemen Pertanian. Jakarta. 